\title{
VIRTUAL CORPORATE TRAINING SYSTEMS
} Defining Criteria and Indicators for Evaluation

\author{
Marina Keiko Nakayama, Christine da Silva Schröeder, Bianca Smith Pilla, \\ Daniel Garcia Haro and Erlaine Binotto \\ PPGA/EA/UFRGS - Universidade Federal do Rio Grande do Sul Rua Washington Luiz,- \\ Porto Alegre/RS - Brazil marina@ea.ufrgs.br, christine@ea.ufrgs.br, bspilla@ea.ufrgs.br. \\ dharo.ez@terra.com.br and erlaine@ufrgs.br
}

Abstract: The objective of this study is to identify criteria and indicators to evaluate distance education programs used in companies. The choice of this subject is justified by current difficulties companies experience in evaluating training, especially virtual training. It provides a correlation between results of this type of training and organizational results. A theoretical base was built on the following aspects: training perspectives and development, structure and evaluation of virtual training and definition of performance indicators emphasizing the model of evaluation of four levels by Kirkpatrick (1998) and the Balanced Scorecard by Kaplan \& Norton (1997). Starting from this conceptual base, the authors conducted exploratory research using techniques of data collection, interviews with distance education specialists, and an analysis of organizational best practice in virtual training. Eight specialists from Brazilian Universities were interviewed and the best practices of thirty two companies were analysed from papers presented to the Congress on Elearning Brazil in 2004. The preliminary results allow establishment of a relation between criteria and relevant indicators for evaluation of this type of training system. The validation of this model will be through a case study of a company using virtual training.

Key words: Distance education, training, evaluation, results.

\section{INTRODUCTION}

For many years, administrative theories have evolved and have been concerned with training of organization collaborators, seeking to use activities which minimize operational flaws in the current administration of knowledge as a tool for sustaining competitive advantages. Training and 
development activities (T \& D) of company employees are characterized as strategic issues. Program methods of T \& D have started to receive new focus. Distance education has been an emerging solution for training. According to Niskier (1999), distance education offers advantages such as reduction of costs, access for a larger number of individuals, integration of different educational resources and the possibility of constant updating. In this sense, an important subject related to the use of distance education in training activities is the measurement of current organizational results in the application of such a methodology. It is necessary to identify the criteria and relevant indicators for this evaluation process.

"What to measure?", "why measure?" and "how to measure?" are relevant subjects for companies. In this context, the evaluation of results involves not only short term goals, but also long periods of guaranteed sustainability of organizational strategy. Even faced with different methodologies of evaluation, it is believed that many companies have difficulty adjusting to this process. The issue is how to appropriately measure training results, especially in virtual training. This ranges from student reactions to the training program, to the way in which new knowledge alters his/her behaviour and work procedures. The result of the financial return is important, because it is the final product of the improvement process and the intellectual capacity of the company.

It is necessary then to work out a process of measuring performance systems of virtual corporate training, consisting of criteria ("what needs to be measured?") and indicators ("what can be used to measure?"). Starting from this point, the research problem is proposed: which criteria and indicators can be used for the evaluation of systems of virtual corporate training?

\section{THEORETICAL REFERENTIAL}

The accomplished research is based on the following aspects.

\subsection{Training and Development Perspectives}

The management of human resources in the last 10 years has had a larger involvement in the executive decision processes aiming for results through the alignment of human potential with the strategic focus of the organization. To Bohlander, Snell and Sherman (2003), the term "training" is frequently used in a casual way to describe the efforts of a company to stimulate its members to learn. However, many specialists make the distinction between 
training focused on subjects related to performance in the short-term, and development focused on the enhancement of an individual's ability in the long term. According to Marras (2001), training is aligned with tasks, and a development program offers a person an overview of the business. Both have been combined in a single expression - "training and development" - to indicate all of the activities that increase the foundation of employees' abilities in companies.

\subsection{Structure and Evaluation of Virtual Training}

The structure of a training program can be defined through four basic stages (Bohlander, Snell and Sherman 2003): evaluation of needs, the project, implementation, and evaluation of training. In the last one, the four levels proposed by Kirkpatrick (1998) are reaction, learning, behaviour and results. To Hack (2000) they can also be adopted to training via the Internet:

- Reaction: The student is evaluated for participation in learning activities, indicating whether he/she is adapting to the form of the material presented. A positive reaction to training is as important for internal instructors training within the company, as for programs offered to the public, because the future of the program depends on this reaction;

- Learning: Learning happens when there is a change in the process of being aware of reality and/or increased knowledge or ability;

- Behaviour: New teaching methods are only good when studied in the context of the student's abilities and attitudes. Similarly, this level tries to identify the changes generated after the student has finished the training program;

- Results: The object of this level, maybe the most complex level, is to identify if the company has obtained a return on its investment. To provide a more complete idea of the impact of learning within the company, indicators can be added like data for market growth, etc.

\subsection{The Importance of Performance Indicators}

Organizations are using different systems of performance evaluation focused on their processes and, consequently, their results. There are methods capable of evaluating organizational excellence with a wider view than just the financial one: in other words, the operational environment of participants and stakeholders (people, creditors, suppliers and others who have a direct economical bond with the company). In the process of defining criteria and performance indicators, there are some essential considerations regarding indicators, such as their essential characteristics, criteria and 
classification which are focus indicators using the Quality approach (Takashina and Flores 1995; Camargo 2000), and especially the indicators of the Balanced Scorecard approach (Kaplan and Norton 1997).

The Quality approach - Takashina and Flores (1995) argue that an indicator should be generated carefully, in a way that ensures the readiness of the data and more relevant results in the shortest possible time and at the lowest cost. To Camargo (2000) there are essential parameters in the generation of the quality indicators: selectivity or importance; simplicity and clarity; comprehensiveness, traceability and accessibility; comparability; stability, accessibility and affordability.

The Balanced Scorecard (BSC) method consists of a model of evaluation of organizational performance. It has come from conflict between highly competitive functions and static analysis of financial accounting of costs. Scorecard has made possible communication of strategies to the organization in creating a holistic model, based on four main perspectives. They are complementary through a cause and effect relationship, through perspectives of financial, customers, internal processes and learning and growth which are translated into strategic objectives, measured through goals and performance factors. These results give the organization important feedback.

\section{METHOD OF RESEARCH}

This research is characterized as an exploratory and qualitative study. The techniques for collection of data were interviews with distance education specialists and the analysis of cases of virtual corporate training.

The objective of the interviews was to identify relevant aspects in the evaluation of distance education systems used by companies, according to the views of specialists. Forty specialists from universities, consultancies and Brazilian companies were contacted. The sample was characterized by accessibility and convenience. Among the group who were researched, eight interviews took place. To complement the data, 32 papers were analysed describing the operation of distance education systems in Brazilian and multinational companies. Their views were presented during the Congress ELearning Brazil 2004. The phases of the research were:

a) the first phase was bibliographical research seeking to use theoretical reference for orientation and details of a conceptual model of criteria and indicators;

b) the second phase was a collection of data (analysis of the interviews with the specialists and the business practice cases) to explain a skilled model of criteria and indicators; and 
c) the third phase was explanation of final criteria and indicators model. After these phases researchers intend to continue with a case study in which the proposed model will be applied in an organization. The data used for interviews was analysis of documentary sources and content analysis.

\section{DESCRIPTIONS AND ANALYSIS OF RESULTS}

After bibliographical research into the definition of criteria and indicators and analysis of interviews with the distance education specialists, it was verified that: distance education specialists place greater emphasis on evaluation of learning, while the managers of Training and Development defined a larger range of criteria and indicators, especially evaluation of the results. However, this suggested that criteria, rather than specific indicators, were easier to evaluate and therefore there were some gaps between the two.

The reaction stage was more easily analysed by the specialists in the context of the business practice cases. In the behaviour phase, it was observed that it was more difficult to examine criteria and indicators.

As a result of the research up to the present moment, a model composed of criteria and indicators of evaluation of virtual training, which structure is based on training evaluation phases proposed by Kirkpatrick (1998): reaction, learning, behaviour, and results. Such arrangement has resulted from a coalition of criteria and indicators of the revision of literature, interviews with the specialists and analysis of the business practice cases.

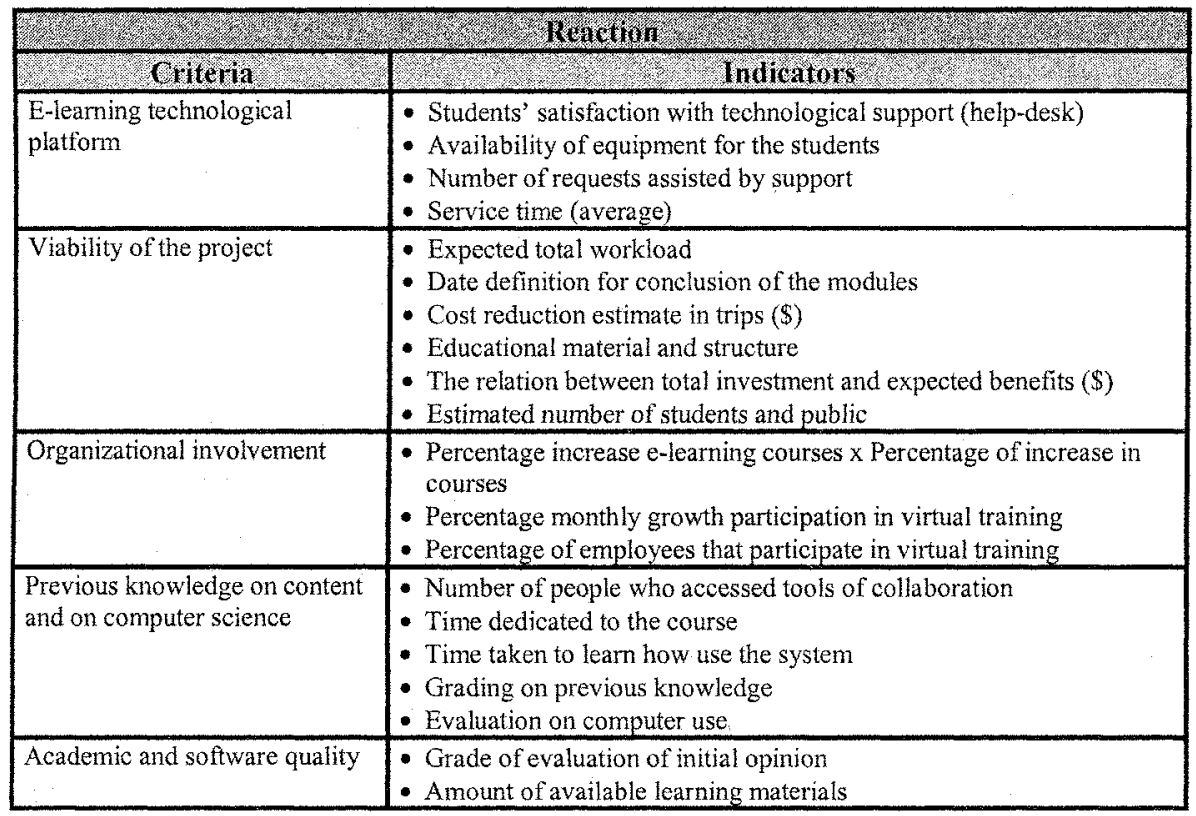




\begin{tabular}{|c|c|}
\hline & - Previous research with specialists, final users and help-desk \\
\hline $\begin{array}{l}\text { Motivational/support for the } \\
\text { tutor and student feedback }\end{array}$ & - Students' satisfaction with their tutor \\
\hline $\begin{array}{l}\text { Personalized teaching in } \\
\text { agreement with the student's } \\
\text { cultural, social, historical and } \\
\text { environmental aspects }\end{array}$ & $\begin{array}{l}\text { - Percentage access by collaborators, partners, relatives, customers } \\
\text { and other users } \\
\text { - Number of students enrolled in virtual training x number of students } \\
\text { in training }\end{array}$ \\
\hline 20 & IVrrungry \\
\hline Criteria & 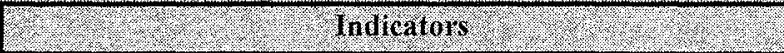 \\
\hline $\begin{array}{l}\text { Students performance (content } \\
\text { domain, autonomy and goals } \\
\text { obtained) }\end{array}$ & $\begin{array}{l}\text { - Test grades of content domain } \\
\text { - Analysis of the composition of papers and reports relating to } \\
\text { content } \\
\text { - Evaluation of the accomplished tasks } \\
\text { - Grading of the students' self-evaluation } \\
\text { - Consensus and feedback tools, tests, self-evaluation and tracking } \\
\text { progress } \\
\text { - Evaluation by the classmates }\end{array}$ \\
\hline $\begin{array}{l}\text { Participation and students } \\
\text { interaction }\end{array}$ & $\begin{array}{l}\text { - Number and quality of participants in interactive tools (chats, } \\
\text { forums, discussion lists, e-mails, etc) } \\
\text { - Evaluation of contribution levels / articulation of a processed idea }\end{array}$ \\
\hline $\begin{array}{l}\text { Adaptation of the levels of } \\
\text { complexity of content, themes } \\
\text { and periods }\end{array}$ & $\begin{array}{l}\text { - Comparative data of the virtual teams for areas and purpose } \\
\text { - Pcriodic evaluation opinion of the participants }\end{array}$ \\
\hline (2) & Therviour. \\
\hline D. & \begin{tabular}{|l|l|l|} 
& Indientors \\
\end{tabular} \\
\hline $\begin{array}{l}\text { Change verification - } \\
\text { relationship / interaction among } \\
\text { virtual communities }\end{array}$ & $\begin{array}{l}\text { Verification of the relationship among classnates } \\
\text { - Numbers and characteristics of the interaction between students } \\
\text { and teachers during and after training } \\
\text { - Use of communication tools for integration of teams and to } \\
\text { facilitate the execution of tasks }\end{array}$ \\
\hline $\begin{array}{l}\text { Change verification - cognitive } \\
\text { structure / organizational culture }\end{array}$ & $\begin{array}{l}\text { - Students daily activity evaluation including behaviour } \\
\text { - Self-evaluation of the student at the end of the course } x \text { periodic } \\
\text { self-evaluation during the course }\end{array}$ \\
\hline $\begin{array}{l}\text { Students motivational aspect / } \\
\text { attitude the virtual mode of } \\
\text { training }\end{array}$ & $\begin{array}{l}\text { - Periodic evaluation of opinion } \\
\text { - Evaluating motivation to undertake new virtual courses } \\
\text { - Final Percentage of access collaborators, partners, relatives and } \\
\text { other users } \\
\text { - Comparison of initial motivation x motivation during the program }\end{array}$ \\
\hline Execution of processes & $\begin{array}{l}\text { - Process attendance } \\
\text { - Ranking of team performance }\end{array}$ \\
\hline 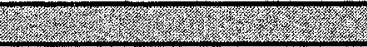 & Nesilts \\
\hline Criteria & Indicators \\
\hline Performance analysis & $\begin{array}{l}\text { - Self-evaluation and final evaluation } \\
\text { - Audit evaluation }\end{array}$ \\
\hline $\begin{array}{l}\text { Continuous improvement - } \\
\text { customers }\end{array}$ & $\begin{array}{l}\text { - Percentage Increase the customer bases } \\
\text { - Market share }\end{array}$ \\
\hline $\begin{array}{l}\text { Continuous improvement-- } \\
\text { processes }\end{array}$ & $\begin{array}{l}\text { - Number of completed processes } \\
\text { - Percentage reduction in mistakes / defects / infringement of } \\
\text { procedures } \\
\text { - Number of new products and services } \\
\text { - Time reduction percentage in the execution of processes } \\
\text { - Re-work volume }\end{array}$ \\
\hline
\end{tabular}




\begin{tabular}{|l|l|}
\hline & - Amount of overtime \\
\hline $\begin{array}{l}\text { Continuous improvement - } \\
\text { communication }\end{array}$ & - Optimization of the use of communication tools and data bases \\
\hline $\begin{array}{l}\text { Practical usefulness on } \\
\text { knowledge / student autonomy } \\
\text { at the conclusion of this process } \\
\text { /personal and professional } \\
\text { development }\end{array}$ & $\begin{array}{l}\text { - Percentage of previous knowledge x percentage of the final } \\
\text { evaluation of knowledge }\end{array}$ \\
& $\begin{array}{l}\text { Exercise and assembly of experiments } \\
\text { - Simulation of situations in the virtual environment } \\
\text { - Time taken to answer the tasks } \\
\text { - Verification of attitude changes in the daily activities after } \\
\text { completion of the course }\end{array}$ \\
\hline Return on the Investment & $\begin{array}{l}\text { Index comparison of the use of the environment and students' } \\
\text { practical results }\end{array}$ \\
\hline $\begin{array}{l}\text { Improvement of the } \\
\text { organizational image / social } \\
\text { responsibility / digital inclusion }\end{array}$ & $\begin{array}{l}\text { - Percentage increase in profitability } \\
\text { - Percentage loss and gains regarding competition }\end{array}$ \\
\hline Value of the human resources & $\begin{array}{l}\text { Research of the internal and external customer's satisfaction } \\
\text { - Tumber of courses in process and new planned courses }\end{array}$ \\
\hline
\end{tabular}

Figure 1: Final criteria and indicators model for the evaluation of virtual training

(Source: Details from the theoretical reference and the collection of data)

\section{FINAL CONSIDERATIONS}

The presented model has expressed the effort of listing maximum possible relevant criteria and indicators for evaluation of virtual training in the organizations. It was also established specific indicators related to each criterion, being that some are repeated for different criteria. However, the study has pointed out that the definition of indicators is still inexact for four criteria, as the evaluation of each is more directly linked to the particularities of organizational reality:

- Safety tools - access, authentication, authorization, audit (in the Reaction stage): the safety tools to be implanted in the system depends on the definitions of strategic, tactical and operational training traced by the management of HR with the high managers of the company.

- Scales of classification with behavioural anchor (in the Behaviour stage): the desired levels of behaviour are defined from the organizational mission and vision of each company;

- Attitude related to content (in the Behaviour stage): the criteria of evaluation of the desired attitude will be conceived from the definition the organizational standards of behaviour mentioned previously;

- Alignment with HR subsystems and the integration of platform to other corporate systems and holistic vision of the business (in the Results stage): the definition of criteria is extremely complex as to the 
means that broad knowledge on the Strategic Planning of the company becomes necessary, as well as the adjusted virtual structure on processes to other subsystems of HR, like remuneration, positions and salary, benefits, etc.

In this sense, it is suggested a subsequent validation of group criteria and indicators in a company which uses virtual corporate training. At it shows, the model presented a list of criteria and indicators, which can be adapted to the reality and culture of each organization intending to measure its system of virtual training. This way, each organization can define its criteria and respective indicators. This analysis will interact with the criteria and indicators of the global results indicators which need to be adapted to the reality and culture of each organization intending to measure its system of virtual training. The criteria and indicators are evidences of cause and effect. To convert training into results will be a constant challenge for the companies. Next phase of this research is the construction of an evaluation model of a specific company in Brazil respecting its business, culture and reality. The company is the wholesale business segment.

\section{REFERENCES}

Bohlander, G.; S. Snell \& A. Sherman (2003) Administração de recursos humanos, Pioneira Thomson Learning, São Paulo.

Camargo, L. L. (2000) Uso de indicadores da qualidade para o gerenciamento estratégico de empresas do ramo comercial, Programa de Pós-Graduação em Engenharia de Produção, Universidade Federal de Santa Catarina (UFSC), Florianópolis. [http://teses.eps.ufsc.br/defesa/pdf/4429.pdf]

Hack, L. E. (2000) Mecanismos complementares para a avaliação do aluno na educação a distância, Curso de Pós-Graduação em Ciência da Computação, Instituto de Informática, Universidade Federal do Rio Grande do Sul (UFRGS), Porto Alegre.

Kaplan, R. S. \& D. P. Norton (1997) A estratégia em ação - Balanced Scorecard, Campus, Rio de Janeiro.

Kirpatrick, D. L. (1998) Evaluating training programs: the four levels (Second Edition), Berret-Koehler Publishers Inc., San Francisco, CA.

Marras, J. P. (2001) Administração de recursos humanos: do operacional ao estratégico, Futura, São Paulo, pp.145-172.

Niskier, A. (1999) Educação a distância: a tecnologia da esperança. Edições Loyola, São Paulo.

Takashina, N. T. \& M. C. X. Flores (1995) Indicadores da qualidade e do desempenho, Qualitymark, Rio de Janeiro. 